\title{
Caracterização socioespacial da produção e comercialização de hortícolas na Ilha de São Luís, Maranhão
}

Socio-spatial characterization of the production and commercialization of vegetables in the Island of São Luís, Maranhão

\author{
J. F. B. Gomes ${ }^{1 *}$; A. O. Souza ${ }^{2}$; R. S. B. Gomes ${ }^{3}$ \\ ${ }^{1}$ Setor de Transferência de Tecnologia, Empresa Brasileira de Pesquisa Agropecuária, CEP: 65065-470, São Luís- \\ Maranhão, Brasil \\ ${ }^{2}$ Departamento de Arquitetura e Urbanismo, Universidade Estadual do Maranhão, CEP: 65055-970, São Luís- \\ Maranhão, Brasil \\ ${ }^{3}$ Setor de Pesquisa, Empresa Brasileira de Pesquisa Agropecuária, CEP: 65065-470, São Luís-Maranhão, Brasil
}

*joaoflavio.gomes@embrapa.br

(Recebido em 02 de janeiro de 2018; aceito em 30 de abril de 2018)

\begin{abstract}
$\overline{\text { Objetivou-se conhecer a horticultura urbana praticada na Ilha de São Luís por meio da sua caracterização }}$ socioespacial, bem como suas atividades produtivas, a existência de políticas públicas, apoio do governo ou da iniciativa privada. Realizou-se pesquisa do tipo quantitativa e qualitativa para compreender a agricultura praticada em seus espaços, e os atores no atual modelo de planejamento urbano do município. O percurso metodológico consistiu na realização de pesquisa bibliográfica, pesquisa de campo e análise qualitativa e quantitativa dos dados. As informações coletadas foram tabuladas, e foram elaborados mapas temáticos, com o auxílio dos softwares QGis e Google Earth. Concluiu-se que há grande potencial para o desenvolvimento da horticultura urbana na Ilha de São Luís, porém é evidente a necessidade de discussão e elaboração de políticas públicas nas áreas de infraestrutura urbana (transporte e estradas de boa qualidade), treinamento dos produtores para a sua inserção em programas públicos como o Programa Nacional de Alimentação Escolar (PNAE) e Programa de Aquisição de Alimentos (PAA), fornecimento de assistência técnica continuada, com foco em Agroecologia. Há uma fragmentação entre a produção e a comercialização, que poderia ser minimizada com a cessão de espaços públicos privados, ociosos ou não, para a instalação de hortas comunitárias que permitiria a aproximação entre a produção e comercialização, reduzindo custos.

Palavras-chave: agricultura urbana, planejamento urbano, produção agrícola, agroecologia
\end{abstract}

The objective was to know the socio-spatial characterization of urban horticulture practiced in the Island of São Luís, as well as its productive activities, the public policies existence, support of the government or private initiative. The common agriculture in their spaces, also the actors in the current urban planning model of the municipality were object to quantitative and qualitative research. The methodological course consisted in the accomplishment of bibliographical research, field research and qualitative and quantitative data analysis. The information collected was tabulated, and thematic maps were elaborated, with the help of the QGis and Google Earth software. It was concluded that there is great potential for the development of urban horticulture in the Island of São Luís, but clearly there is a need for discussion and elaboration of public policies in the areas of urban infrastructure (transport and high quality roads), training of producers for its inclusion in public programs such as the National School Feeding Program and Food Acquisition Program, providing technical assistance with a focus on Agroecology. There is a fragmentation between production and marketing, which could be minimized by the transfer of private public spaces, idle or not, for the installation of community gardens, which would allow the approximation between production and marketing, reducing costs.

Keywords: urban agriculture, urban planning, agricultural production, agroecology

\section{INTRODUÇÃO}

A Ilha de São Luís localiza-se ao norte do estado do Maranhão, região Nordeste do Brasil. Encontra-se situada na Região Costeira do Estado e limita-se ao norte com o Oceano Atlântico; ao sul, com a baía de São José e o Estreito dos Mosquitos; a leste com a baía de São José e a oeste com a baía de São Marcos [1]. Possui uma população de 1.309.330 habitantes e densidade $047601-1$ 
demográfica de $927,11 \mathrm{hab} / \mathrm{km}^{2}$, considerando a somatória dos dados dos municípios da Ilha informados no Censo de 2010, do Instituto Brasileiro de Geografia e Estatística [2]. Os municípios que integram a Ilha são Paço do Lumiar, Raposa, São José de Ribamar e São Luís, essa a capital do Estado e sede regional da Ilha.

O município de São Luís oferece condições edafoclimáticas favoráveis para o cultivo de hortaliças, frutas, plantas medicinais, entre outras culturas. Os polos rurais destacam-se pela grande quantidade existente na chamada zona rural do município, sendo que alguns desses polos sugerem localizar-se em áreas periurbanas. Contudo, a quantidade de áreas produtoras não se traduz em garantia do mínimo satisfatório no abastecimento alimentar interno.

Essa é uma dupla oportunidade para a agricultura urbana e periurbana, visto que, ao estar vinculada conceitualmente à segurança alimentar e à conservação dos recursos naturais, permite que as áreas urbanas também sejam aproveitadas para atividades agrícolas, por meio de técnicas de base agroecológica, as quais produzem alimentos saudáveis, livres de agrotóxicos, evitando a contaminação de fontes de água e do solo das cidades. De acordo com Altieri (2004) [3], as técnicas de base agroecológica são de baixo custo, com eficiência na correção de solos arenosos, como ocorre em parte do município, os quais possuem poucos nutrientes.

Mesmo com boa infraestrutura e excelente localização geográfica, o município sempre apresentou baixa produtividade agrícola, segundo o Diagnóstico socioeconômico da horticultura na Ilha de São Luís [4], produto de uma parceria entre o então governo do Estado do Maranhão e o Serviço Brasileiro de Apoio às Micro e Pequenas Empresas (Sebrae). Nesse contexto, a agricultura urbana e periurbana no município encontra um ambiente favorável para desenvolvimento da economia local. Por meio do programa municipal Feiras Livres, o município oferece um importante local de venda da produção do agricultor familiar, diversificando os locais de ofertas de hortícolas diversas dentro do município e oferecendo produtos saudáveis e frescos, alinhados com o conceito de segurança alimentar. Contudo, o número de produtos importados ainda é alto, conforme indicou a pesquisa de campo, com cerca de 59\% de atravessadores (indivíduos que compram produtos agrícolas e revendem, principalmente em feiras livres) presentes nas feiras do município.

As feiras são entendidas como importante canal de comercialização nos espaços intraurbanos e periurbanos, sendo parte constituinte desse processo de práticas agrícolas urbanas. Além disso, constituem o chamado circuito curto de abastecimento das cidades, apresentando vantagens importantes ao pequeno produtor, especialmente no que se refere ao baixo custo, e para o consumidor, que recebe produtos frescos, colhidos no mesmo dia e que não foram estocados em prateleiras ou galpões [5]. As feiras são, ainda, exemplo de espaço de comercialização que foge ao esquema usual de distribuição dos outros programas comerciais - como supermercados, sacolões e mercados: seu caráter é temporário e sua estrutura possibilita grande capacidade de adaptação a diversas situações.

Além disso, ocupam espaços urbanos com diferentes características (mesmo que por um curto período de tempo), podendo atender tanto a demandas de consumo locais como metropolitanas. Daí o seu potencial em atender tanto ao pequeno comerciante, que não tem a oportunidade de adquirir um ponto comercial dentro desses outros programas comerciais, como a um público específico que busca alternativas de consumo.

A Secretaria Municipal de Abastecimento, Pesca e Agricultura (Semapa) mantém sob sua coordenação as feiras, os mercados municipais, categorizados de acordo com o seu porte (número de feirantes cadastrados que comercializam). Juntamente com os pontos de comercialização particulares e as feiras, compõem o sistema de abastecimento alimentar de São Luís. A escolha das feiras livres de São Luís foi um dos fatores considerados como "porta de entrada" de dados socioeconômicos e ambientais da pesquisa de campo, realizada por meio de entrevistas e aplicação de questionários semiestruturados com os seus feirantes.

Destacou-se outro importante fator de escolha: dentre todos os pontos de comercialização e abastecimento públicos informados pela Semapa, as feiras livres são as que apresentam maiores vantagens econômicas para os pequenos produtores, significando baixo custo para os mesmos. Os mercados públicos de grande, médio e pequeno porte, exigem custos para aquisição de banca de venda, além de outras taxas. Já os mercados particulares, como supermercados, mercearias, armazéns, sacolões etc., ainda são de difícil acesso aos agricultores familiares por exigirem grande 
volume de entrega de produtos, além de requisitos mínimos de embalagem e distribuição, o que inviabiliza o acesso desse mercado ao pequeno produtor.

Objetivou-se conhecer a horticultura urbana praticada em São Luís na sua caracterização socioespacial, bem como suas atividades produtivas, a existência de políticas públicas, apoio do governo ou da iniciativa privada.

\section{MATERIAL E MÉTODOS}

Realizou-se pesquisa do tipo quantitativa e qualitativa para compreender a agricultura praticada em seus espaços, e os atores no atual modelo de planejamento urbano do município. O percurso metodológico consistiu na realização de pesquisa bibliográfica, pesquisa de campo e análise qualitativa e quantitativa dos dados.

Foi realizada em um primeiro momento, a pesquisa exploratória, utilizando as seguintes ferramentas metodológicas: a) da observação de campo; b) da pesquisa documental, por meio de consultas presenciais e virtuais (internet) realizada em alguns órgãos, entre eles Instituto Brasileiro de Geografia e Estatística (IBGE), Instituto Maranhense de Estudos Socioeconômicos e Cartográficos (Imesc), Instituto de Agronegócios do Maranhão (Inagro), Serviço Brasileiro de Apoio às Micro e Pequenas Empresas (Sebrae), Instituto da Cidade, Pesquisa e Planejamento Urbano e Rural (Incid), Empresa Brasileira de Pesquisa Agropecuária (Embrapa), além das secretarias municipais de agricultura e abastecimento, de urbanismo e de planejamento dos quatro municípios; e pesquisa bibliográfica em livros, artigos, dissertações e teses.

Durante a fase da pesquisa bibliográfica e documental buscou-se mais detalhes que convergissem para alguns temas a fim de se tornarem coerentes com a pesquisa exploratória: prática de agricultura nas cidades, políticas públicas de apoio às atividades agrícolas, redes urbanas e desenvolvimento urbano sustentável. Para tal, foi pesquisado na literatura títulos em livros de referência, artigos nacionais e internacionais, dissertações e teses, que trouxessem conceitos, discussões, dados e informações acerca da agricultura urbana e periurbana e sua relação com o espaço urbano.

Para que os dados coletados em campo pudessem ser confrontados com as informações oficiais fornecidas pelos órgãos públicos, foram aplicados questionários nas Feiras Livres do Pequeno Produtor, que fazem parte do programa Feiras Livres de São Luís, mantido pela Secretaria Municipal de Abastecimento [6]. Os números oficiais de feirantes cadastrados no programa, segundo a Semapa [6] são de 109 produtores, incluídos aí os feirantes beneficiados pelo Programa São Luís Rural, e 118 importadores (atravessadores), além de 30 feirantes que comercializam pescados e mariscos, totalizando 257 feirantes.

A população objeto da pesquisa correspondeu especificamente aos produtores e comerciantes de hortícolas, totalizando 227 feirantes (que comercializavam em diversas feiras livres), ou seja, foram excluídos 30 feirantes que comercializavam pescado e marisco, que não eram objeto de estudo dessa pesquisa. Para a definição da amostra a ser pesquisada, utilizou-se a equação para cálculo de amostra para população finita (1), preconizada para pesquisa social com número de população conhecido [7]. De acordo com o cálculo efetuado, chegou-se ao número de amostra mínimo de 118 feirantes, utilizando nível de confiança de $95 \%$ e margem de erro de 5\%.

$$
n=\frac{Z^{2} \times P \times Q \times N}{e^{2} \times(N-1)+Z^{2} \times P \times Q}
$$

Onde:

$\mathrm{Z}=$ Nível de Confiança

$\mathrm{P}=$ Quantidade de Acerto esperado (\%)

$\mathrm{Q}=$ Quantidade de Erro esperado (\%)

$\mathrm{N}=$ População Total

e = Nível de Precisão (\%)

$\mathrm{n}=$ Tamanho da amostra

Definidos população, amostra e local para coleta de dados empíricos, procedeu-se à aplicação do questionário, composto por 42 perguntas, divididas em quatro partes. 
A primeira parte buscou identificar o feirante, categorizando-o em produtor ou atravessador, conhecer o seu perfil socioeconômico, seu conhecimento da existência do Plano Diretor do município de São Luís, e local da sua produção, se no espaço periurbano ou intraurbano do mesmo (Figura 1). Sobre a questão que trata do Plano Diretor, objetivou-se conhecer se houve participação desses atores sociais no processo de elaboração do mesmo sem, contudo, aprofundarse com questões mais específicas.

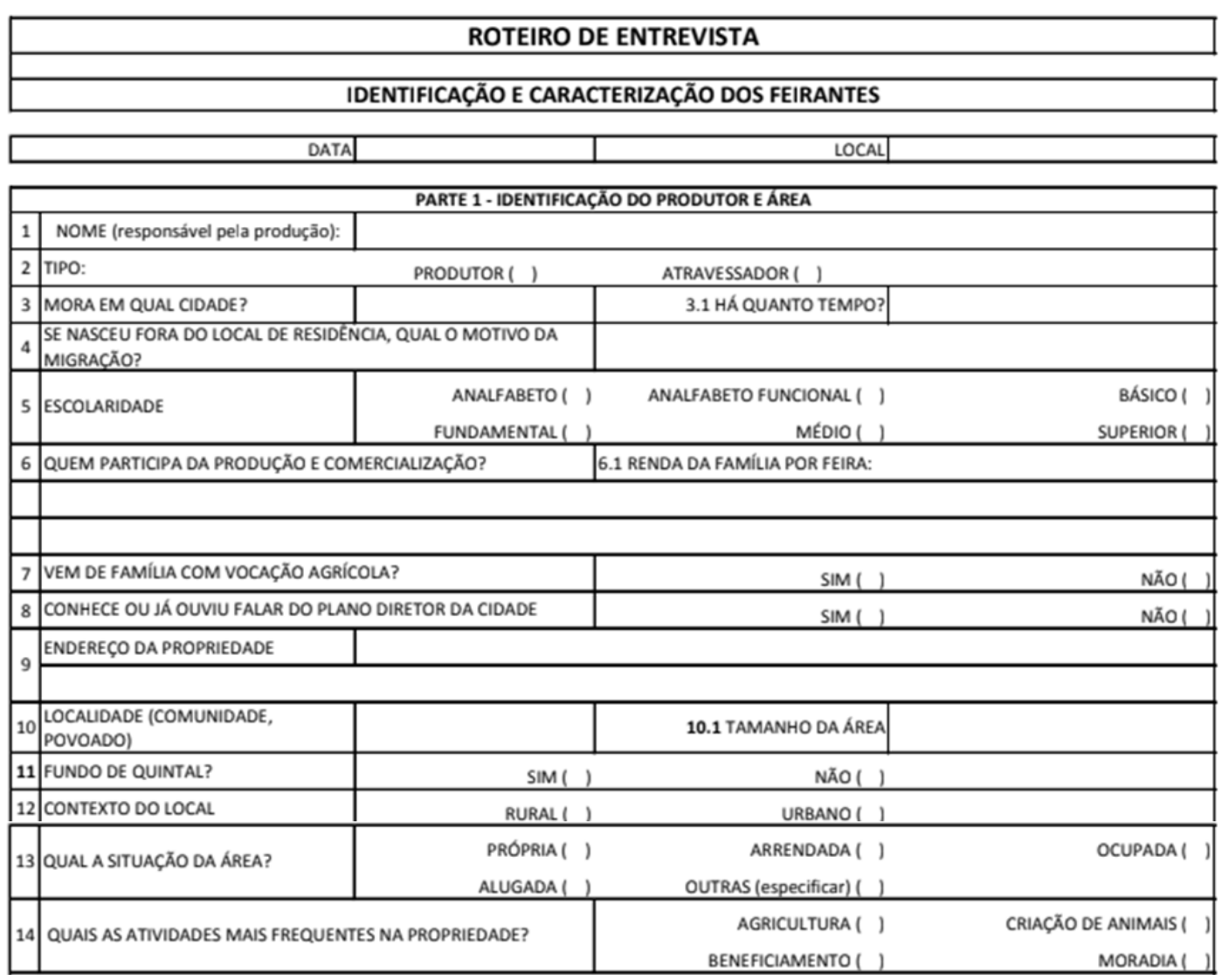

Figura 1: Primeira parte do questionário aplicado contendo 14 questões. Elaborado pelos autores.

A segunda parte visou conhecer a produção daquele feirante que é produtor, e, sendo atravessador, procurou conhecer os produtos redistribuídos (Figura 2). Também investigou quais auxílios governamentais os produtores e atravessadores recebem, bem como os programas voltados para os agricultores e assistência técnica agronômica, além de questões sobre aplicação de produtos químicos, técnicas agroecológicas.

A terceira parte buscou identificar para onde a produção é distribuída e onde é comercializada, qual a frequência e qual a renda gerada (Figura 3) e, por fim, na quarta parte do questionário procurou-se conhecer a percepção dos feirantes sobre o efetivo apoio governamental que os produtores recebem do governo (Figura 4).

As informações coletadas foram tabuladas, e foram elaborados mapas temáticos. Os mapas informam a localização das áreas de produção e de comercialização e foram elaborados com o auxílio dos softwares QGis e Google Earth. 


\begin{tabular}{|c|c|c|c|c|}
\hline \multicolumn{5}{|c|}{ PARTE 2 - IDENTIFICAÇÃO DA PRODUÇ̄̄o } \\
\hline 15 & O QUE PRODUZ OU REVENDE & 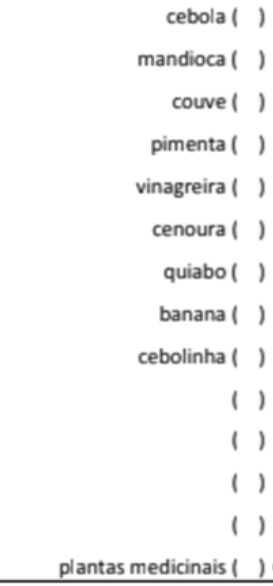 & $\begin{array}{rr}\text { tomate( ) } \\
\text { alface ( ) } \\
\text { cheiro-verde ( ) } \\
\text { batata ( ) } \\
\text { manga ( ) } \\
\text { chuchu ( ) } \\
\text { laranja ( ) } \\
\text { pimentão ( ) } \\
\text { acerola ( ) } \\
\text { ( ) } \\
\text { ( ) } \\
\text { ( ) } \\
\text { ( ) }\end{array}$ & 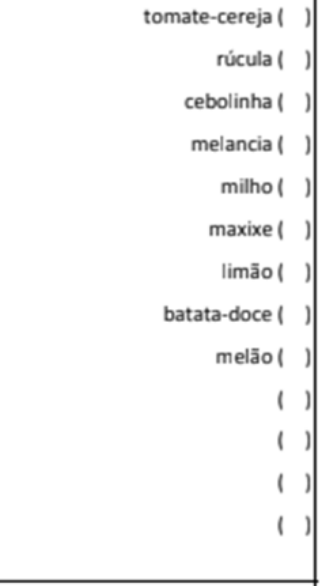 \\
\hline 16 & APLICA PRODUTOS QUÍMICOS? & & $\operatorname{sim}(1)$ & NÃO( ) \\
\hline 17 & SE SIM, QUAIS? & & & \\
\hline \multicolumn{3}{|c|}{18 USA ALGUMA TÉCNICA AGROECOLOGGICA? } & $\sin ()$ & NÃO( ) \\
\hline 19 & SE SIM, QUAL? & \multirow{2}{*}{ 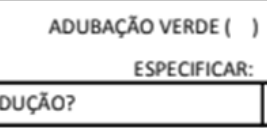 } & COMPOSTAGEM（） & OUTRA( ) \\
\hline \multirow{2}{*}{20} & HÁ RECICLAGEM DO EXCEDENTE DA PRODUÇÃO? & & $\sin (1)$ & NÃO( ) \\
\hline & COMO É REALIZADA? & & & \\
\hline \multirow{4}{*}{23} & \multicolumn{2}{|l|}{ QUAL A FONTE DE ÁGUA PARA IRRIGAÇÃO? } & $\begin{array}{l}\text { POÇO ARTESIANO ( ) } \\
\text { RIO__ } \\
\text { CÓRREGO } \\
\end{array}$ & $\begin{array}{r}\text { REDE PÚBLICA( ) } \\
\text { CISTERNA( ) } \\
\text { MINA OU NASCENTE D'ÁGUA( } \\
\end{array}$ \\
\hline & \multirow{3}{*}{ PRODUZ PROXIMOA A } & \multicolumn{2}{|c|}{ AMBIENTES POLUIDOS( Q QUAL? } & \\
\hline & & \multicolumn{2}{|c|}{ MINHACASA MINHA VIDA( ) } & \\
\hline & & \multicolumn{2}{|c|}{ UNIDADES DE CONSERVAÇ̃̃O () QUAL? } & \\
\hline 24. & RECEBE AUXÍLO DO GOVERNO? & & $\sin (1)$ & NÃO) (1) \\
\hline 25 & SE SIM, QUAL? & & & \\
\hline 26 & \multicolumn{2}{|l|}{ PARTICPA DE PROGRAMA DO GOVERNO? } & $\sin (1)$ & NÃO( ) ( ) \\
\hline 27 & SE SIM, QUAL? & & & \\
\hline 28 & CONTA COM ASSISTENCIA TÉCNICA? & $\begin{array}{l}\text { MUNICIPALI I) } \\
\text { PARTICULAR（） }\end{array}$ & $\begin{array}{r}\text { ESTADUAL ( ) } \\
\text { ONG ( ) }\end{array}$ & FEDERAL( ) \\
\hline 29 & COMO OCORRE A ASSISTENCIA? & & & \\
\hline 30 & SE POSSIVELL, VOCE PLANTARIA EM ÁREA & S DENTRO DE SÃO LUIS? & $\sin (1)$ & NÃO( ) \\
\hline 31 & POR QUE? & & & \\
\hline
\end{tabular}

Figura 2: Segunda parte do questionário aplicado contendo 17 questões. Elaborado pelos autores.

\begin{tabular}{|c|c|c|c|c|}
\hline \multicolumn{5}{|c|}{ PARTE 3 - IDENTIFICAÇÃO DA DISTRIBUIÇÃO E COMERCIAUZAÇÃO } \\
\hline 32 & COMO A PRODUÇÃO É TRANSPC & & $\begin{array}{r}\text { VEÍCULO PROPRIO( ) } \\
\text { VEICCULO DO GOVERNO( ) }\end{array}$ & $\begin{array}{l}\text { VEICULO EMPRESTADO ( ) } \\
\text { VEICULO FRETADO ( }\end{array}$ \\
\hline 33 & QUAIS AS CIDADES ONDE A PRO & & $\begin{array}{r}\text { SÃO LUIS( ) } \\
\text { RAPOSA ( ) } \\
\text { OUTRA (especificar) ( ) }\end{array}$ & $\begin{array}{r}\text { PAÇO DO LUMIAR( , ) } \\
\text { SÃO JOSÉ DE RIBAMAR( ) }\end{array}$ \\
\hline 34 & EM QUAIS OUTRAS FEIRAS OS P & NDIDOS? & & \\
\hline 35 & QUAIS OS PONTOS DE VENDA? & $\begin{array}{l}\text { FEIRAS( ) } \\
\text { OUTRO( ) }\end{array}$ & $\begin{array}{l}\text { SUPERMERCADO( ) } \\
\text { ICAR: }\end{array}$ & SACOLÃO( ) \\
\hline 36 & QUAL A FREQUENCIA E ONDE? & $\begin{array}{r}\text { SEGUNDAI ) } \\
\text { QUINTA-FEIRA( ) }\end{array}$ & $\begin{array}{r}\text { TERÇA ( ) } \\
\text { SEXTA-FEIRA() }\end{array}$ & $\begin{array}{l}\text { QUARTAI ) } \\
\text { SÁBADO( ) }\end{array}$ \\
\hline
\end{tabular}

Figura 3: Terceira parte do questionário aplicado contendo cinco questões. Elaborado pelos autores. 


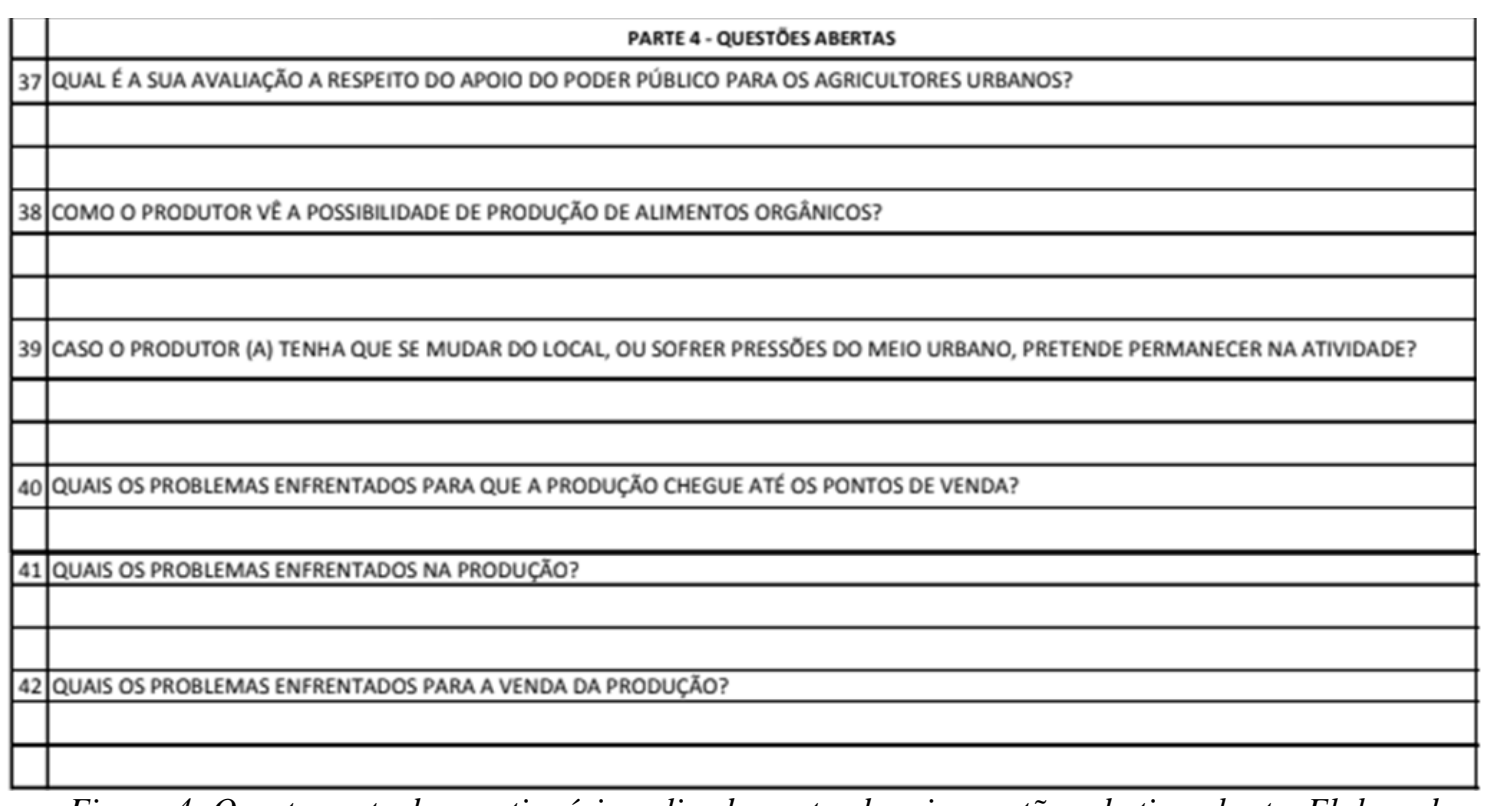

Figura 4: Quarta parte do questionário aplicado contendo seis questões, do tipo aberta. Elaborado pelos autores.

\section{RESULTADOS E DISCUSSÃO}

De acordo com a pesquisa de campo, de um total de 118 feirantes entrevistados, 48 (36\%) são produtores e 70 (64\%) são atravessadores. Percebe-se que o maior beneficiado não é aquele que produz, mas sim o que detém as condições da comercialização, indicando falta de incentivo governamental, planejamento urbano e/ou problemas para a viabilidade da produção agrícola local, devido a custos da produção, baixa qualificação dos produtores, fornecimento de insumos e limitações climáticas e tecnológicas. A maioria dos produtores informou que residem em Paço do Lumiar, seguida de São Luís. Já os atravessadores moram, em sua maioria, no município de São Luís, seguido de Paço do Lumiar.

Como a quase totalidade dos produtores cultivam as hortícolas onde residem, concluiu-se que a maior parte da produção é cultivada no município de Paço do Lumiar, integrante da Ilha de São Luís e de sua Região Metropolitana, distante $26 \mathrm{~km}$ da Capital do estado do Maranhão. O resultado demonstra a importância desse município para o abastecimento alimentar de hortícolas no município de São Luís. Ademais, pode-se inferir que, por conveniência e oportunidade, os atravessadores assumem esta profissão, tendo em vista que o Ceasa de São Luís (Cohortifruti) é o principal fornecedor de seus produtos, facilitando, assim, o trabalho. Do mesmo modo, os atravessadores provenientes de Paço do Lumiar possuem grande número de produtores em sua vizinhança como fornecedores.

No entanto, foi clara a resistência que os atravessadores demonstraram ao responderem o questionário. Enquanto 13\% dos produtores não quiseram informar a renda mensal da família (incluindo outras atividades), $33 \%$ dos atravessadores se negaram a fornecer esta informação, o que poderia mudar este panorama. De qualquer forma, devido aos produtores possuírem famílias maiores, há a necessidade de incremento de renda.

Referindo-se à tradição agrícola, herdada de pai para filho, observou-se que $81 \%$ dos produtores entrevistados possuem vocação familiar, ao passo que entre os atravessadores, $50 \%$ não possuem e $7 \%$ não sabem informar se algum familiar foi produtor. Um dado importante é que $43 \%$ dos mesmos possuem vocação agrícola familiar, mas que abandonaram a atividade agrícola, o que sugere futuras pesquisas que possam esclarecer os motivos para esse fato.

Esses locais são tradicionalmente agrícolas e, assim, devido a essa concentração de produtores familiares, é mais fácil planejar, executar e gerir o planejamento urbano desses municípios, contemplando tais localidades.

Quanto aos atravessadores, observou-se que, igualmente, grande parte reside em Iguaíba, bairro do município de Paço do Lumiar, e no Maracanã, bairro do município de São Luís, 
corroborando com a afirmação acima, favorecendo o fornecimento de transporte, bem como melhorias no trânsito para favorecer o fluxo dos produtos até as feiras, bem como outras ações que serão discutidas posteriormente.

Reportando-se ao contexto da área de produtores e atravessadores, observou-se que a maior parte de ambos localiza-se em áreas rurais. No entanto, destacam-se os produtores com 83\%, ao passo que os atravessadores, menos da metade dessa percentagem, residem em áreas rurais (41\%), sendo ainda maior que em áreas urbanas (33\%). Todavia, deve-se atentar para o fato de que $26 \%$ desses últimos não quiseram responder, como já informado, demonstrando resistência para dar informações. Da mesma forma, quanto à situação da área, $46 \%$ dos atravessadores não quiseram responder a esta pergunta e uma maior percentagem dos atravessadores (49\%) possuem moradia própria.

A maioria dos produtores e atravessadores comercializa em São Luís (77\% e 83\%, respectivamente), seguido de Paço do Lumiar (21\%) para os produtores e 3\% para os atravessadores, sendo que $14 \%$ dos últimos não quiseram responder. Os resultados são um indicativo de que a gestão dos dois municípios devem contemplar tanto produtores como atravessadores em seu planejamento urbano, pois são protagonistas na economia local.

Considerando que o conceito de agricultura urbana proposto por Mougeot (2000) [5] abrange tanto a produção quanto a distribuição e comercialização, além do que foi observado no resultado da pesquisa de campo e documental, é possível afirmar que o município de São Luís é o principal escoadouro da produção agrícola urbana proveniente na sua maior parte do município de Paço do Lumiar, mas também que recebe os produtos provenientes dos demais municípios da Ilha (Figura 5).

No contexto do espaço urbano, observou-se que as áreas produtoras localizam-se em espaço periurbano (periferia) e as áreas de comercialização encontram-se localizadas em áreas intraurbanas (Figura 5). Tal constatação permite proposições interessantes ao planejamento urbano na Ilha de São Luís como, por exemplo, a revisão dos planos diretores de Paço do Lumiar, São José de Ribamar e Raposa, no sentido de adequarem-se ao Estatuto da Cidade (2008) [8]. A adequação abrangeria itens como a participação da comunidade no processo de elaboração, o acesso à cidade e a função social da cidade e da propriedade, além da inserção da política de articulação e integração metropolitana, de modo que a relação local de produção - local de comercialização seja discutida e incentivada, objetivando a melhoria de seus indicadores socioespaciais.

Os bairros onde mais produtores comercializam são Cohab, Praia Grande e Vinhais, todos localizados no município de São Luís. Dessa forma, pode-se gerar um fluxo entre os locais de produção e de comercialização, por parte do poder público, criando ações para que esse fluxo seja facilitado, bem como o acesso dos compradores ao mesmo. Além disso, há maior número de bairros onde os produtores comercializam, em detrimento dos atravessadores ( 23 bairros). Referindo-se aos atravessadores, observou-se os mesmos bairros citados, corroborando com a afirmação acima de facilitar o fluxo das mercadorias dos bairros para as feiras, o acesso dos compradores nas mesmas, bem como melhorar a sua infraestrutura, descarte do lixo e reciclagem, visando à sustentabilidade. 


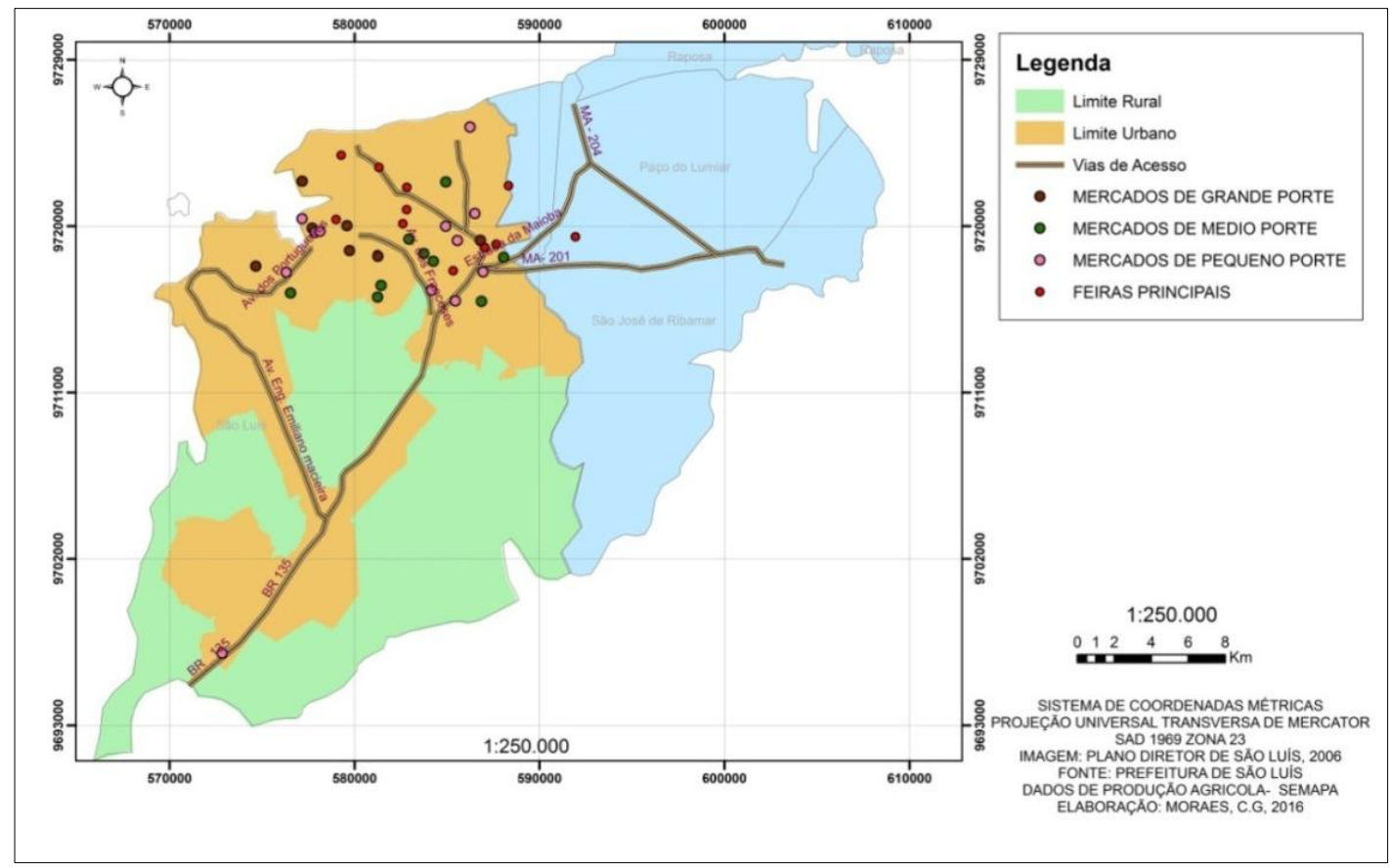

Figura 5: Mapa de Comercialização agrícola em São Luís, de acordo com Secretaria de Agricultura, Pesca e Abastecimento de São Luís (Semapa), São Luís, Maranhão, Brasil, 2016.

Os produtores afirmaram que os principais problemas para que os produtos cheguem até as feiras são o transporte e a estrada, enquanto a maior porcentagem de atravessadores não respondeu. Quando questionados sobre o veículo utilizado para transporte das hortícolas para as feiras, tanto produtores como atravessadores (44\% e 48\%, respectivamente) afirmaram utilizar veículo fretado, sendo que $35 \%$ dos produtores e $32 \%$ dos atravessadores possuem veículo próprio. Quanto à utilização de veículo disponibilizado pelo governo, $17 \%$ dos produtores e apenas 3\% dos atravessadores fazem o uso dos mesmos, sendo necessário um estudo mais aprofundado para entender os motivos dessa decisão.

Os entrevistados relataram diversos problemas e obstáculos que enfrentam diariamente no fluxo produção - comercialização, entre eles falta de veículo próprio e de terceiros (frete) para transporte da produção, estradas vicinais de difícil tráfego, especialmente no período de chuvas, tráfego lento, falta de apoio dos governantes para transporte, etc.

A pesquisa de campo mostrou uma fragmentação espacial entre a produção e a comercialização. A produção concentra-se nas áreas periurbanas de São Luís e na zona rural de Paço do Lumiar, enquanto que a comercialização destes produtos ocorre em sua maioria na área intraurbana de São Luís (Figura 6). Dentro do processo de comercialização, também as feiras se encontram dispersas nessa área intraurbana de São Luís (Figura 5).

O modelo de planejamento urbano de São Luís ainda segue a matriz modernista/funcionalista na qual, segundo Maricato (1999 in Arantes et al, 2013) [9], o Estado é a figura central e que "evitaria as disfunções do mercado como o desemprego (regulamentando o trabalho, promovendo políticas sociais), bem como asseguraria o desenvolvimento econômico e social. Contudo, ainda segundo Maricato, tal modelo apenas contribuiu, historicamente, para que no Brasil a cidade real permanecesse oculta e para o surgimento de um mercado imobiliário "restrito e especulativo". Dessa forma, o Plano Diretor de São Luís [10] é o produto concreto dos interesses de uma parcela da população, e que não atende ao agricultor familiar, pois sua lógica de setorização de funções (zoneamento e uso do solo) é a mesma lógica capitalista que favorece a segregação espacial, concentrando as atividades de produção para o abastecimento alimentar da cidade nas áreas periféricas ou no campo. 


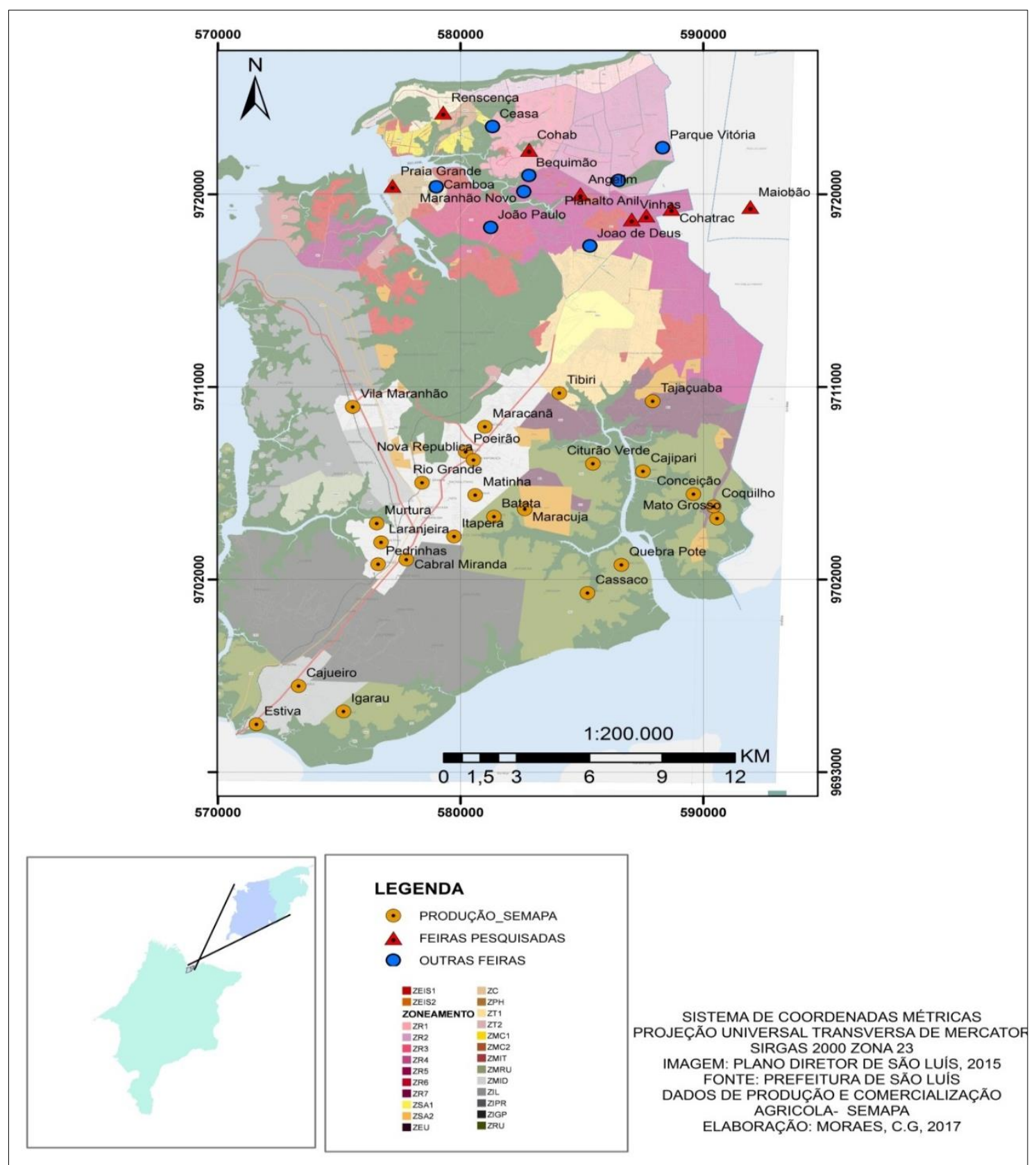

Figura 6: Mapa ilustrando a fragmentação entre a produção e a comercialização de hortícolas na Ilha de São Luís, Maranhão, Brasil, 2016.

A maioria dos produtores possui área própria para cultivo (92\%), indicando a vocação e a estabilidade dos mesmos para adotarem esta profissão, o que favorece a formatação de políticas públicas pelo governo, incluindo o planejamento urbano, e a adoção das mesmas pelos produtores.

Referindo-se ao Plano Diretor do Município, um dos instrumentos de planejamento urbano, $90 \%$ dos produtores e $77 \%$ dos atravessadores não possuem conhecimento da sua existência, o que sugere a exclusão desses atores sociais no seu processo de revisão ocorrido em 2006. Também evidenciou o desconhecimento sobre seus direitos de serem contemplados com ações no planejamento urbano, visando melhoria na infraestrutura urbana de atendimento à produção, distribuição e comercialização, materializadas na melhoria das condições de trabalho, fluxo da distribuição e estrutura das feiras.

Essa relação pode e deve ser considerada em políticas de planejamento urbano, especialmente o planejamento metropolitano, visto que somente o Plano Diretor de São Luís prevê uma articulação entre os municípios da Ilha e outros que porventura venham a integrar a Região Metropolitana de São Luís: 
"embora não existam diagnósticos identificando a situação do município no contexto metropolitano, com ênfase nos problemas de coordenação e cooperação entre os municípios, o Plano Diretor em seu Art. 4 ', inciso IV, prevê: 'ampliar as ações governamentais, promovendo a integração e a cooperação com o governo Federal, Estadual e com os Municípios da Região Metropolitana, no processo de planejamento e gestão das questões de interesse comum." [11].

Dentre os atravessadores, $20 \%$ não responderam ao questionário, novamente indicando certa resistência a fornecerem informações sobre o tema.

Quanto às espécies mais produzidas, a vinagreira, o cheiro-verde e o maxixe destacam-se nas três primeiras posições. Estas espécies são regionais, devido à facilidade de cultivo por adaptação ao clima e solos da região, e, assim, apresentam baixo custo de produção. Ademais, são tradicionais na culinária maranhense, culturalmente transmitidos de geração a geração - tanto o cultivo quanto a culinária. Tomate e cebola são as hortícolas mais comercializadas pelos atravessadores. Essas culturas não são tão comuns de serem produzidas na região, devido à forte pressão de pragas e doenças - propícias às condições climáticas locais, e o mercado disponibiliza poucas cultivares adaptadas. Assim, são importadas de outros Estados produtores pela Cohortifruti de São Luís [12] e recompradas pelos atravessadores.

Com relação aos auxílios fornecidos pelo governo, $50 \%$ dos produtores não os recebem enquanto que $48 \%$ são assistidos e, entre esses, $83 \%$ recebem bolsa família. Excluindo-se os auxílios do governo, $63 \%$ dos produtores asseguraram que não há apoio do poder público, $17 \%$ afirmaram ser muito pouco, $10 \%$ disseram ser bom e outros $10 \%$ não responderam.

Quanto aos atravessadores, 47\% não quiseram responder se recebem auxílio do governo, 39\% afirmaram não receber, enquanto $14 \%$ recebem. A alta de taxa de resistência quanto às questões econômicas sugere o receio de perder algum benefício que possuem. Apesar de tal resistência não comprometer o alcance dos objetivos da pesquisa, sugere-se a realização de estudos sociais mais aprofundados que abordem a relação entre a população beneficiada e os auxílios promovidos pelos Governos.

O Bolsa Família assiste $73 \%$ dos que responderam receber auxílio, enquanto $18 \%$ são aposentados e 9\% recebem o Vale-gás. Assim, pode-se destacar o Bolsa Família como o maior meio de assistência social por parte do governo entre os produtores e os atravessadores que recebem auxílio. Referindo-se às questões estritamente aplicadas aos produtores, inerentes à suas atividades, quando questionados se participavam de programas de governo destinados à compra de produtos oriundos da agricultura familiar, 56\% revelaram que não participam. Entre esses, muitos afirmaram desconhecer os programas e alguns já participaram.

Dentre os que fazem parte, 68\% são assistidos pelo Programa de Aquisição de Alimentos (PAA), 20\% pelo Programa Nacional de Abastecimento Escolar (PNAE) e 12\% pelo Programa Nacional de Fortalecimento da Agricultura Familiar (Pronaf). Observou-se que a maioria dos produtores recebe Bolsa Família, porém não participa de programas do governo direcionados aos agricultores familiares (PAA, PNAE e Pronaf). Para participar destes programas do governo, é necessário produzir uma quantidade mínima de cada produto e garantir frequência do fornecimento do mesmo.

Outro dado importante, é que metade dos produtores não recebe assistência técnica agronômica, o que contribui para uma baixa produtividade, resultando em menor quantidade de produtos a serem comercializados, culminando em renda mais baixa, uma clara indicação de que o governo deve, com urgência, melhorar sua atuação na região. A falta de assistência técnica também tem impacto na esfera ambiental, visto que os produtores não recebem informações de como descartar adequadamente embalagem de agrotóxicos, bem como da quantidade correta dos mesmos a serem aplicados, além de não terem acesso ao conhecimento e aplicação de técnicas sustentáveis de cultivo.

Dentre os $36 \%$ que recebem assistência de um agrônomo ou técnico agrícola, a metade destes é do governo estadual, $32 \%$ municipal e $9 \%$ federal. No entanto, $36 \%$ recebem esporadicamente a visita do técnico, $23 \%$ possuem assistência semanal, $4 \%$ quinzenal, $9 \%$ mensal e 5\% trimestral. 
Dessa forma, pode-se avaliar que, em sua grande maioria, é de baixa frequência a assistência agronômica recebida pelos produtores de hortícolas da Ilha de São Luís.

Reportando-se às questões ambientais e de saúde, $69 \%$ dos produtores não aplicam produtos sintéticos e $31 \%$ fazem o uso dos mesmos. Esse dado merece reflexão quanto à dose aplicada de agrotóxicos, já que grande parte não recebe assistência técnica e se respeitam o período de carência - ou intervalo de segurança, ou seja, é o número de dias que deve ser respeitado entre a última aplicação e a colheita. O período de carência vem escrito na bula do produto e observar o prazo é importante para garantir que o alimento colhido não possua resíduos acima do limite máximo permitido. Ainda, pode-se questionar se o uso de Equipamento de Proteção Individual (EPI) está sendo feito, de maneira a assegurar a saúde dos produtores que aplicam o(s) produto(s).

Sobre a reciclagem das hortícolas que sobram nas feiras livres, $65 \%$ dos produtores e $76 \%$ dos atravessadores afirmaram fazê-la. No entanto, $70 \%$ desses últimos não quiseram responder, ao passo que apenas $4 \%$ dos produtores não responderam. Dos produtores que reciclam, $59 \%$ doam e $44 \%$ dos atravessadores revendem em outro local, como, por exemplo, na porta de casa. A implantação de um programa de arrecadação de alimentos da sobra, no âmbito da integração de políticas e programas públicos, poderia destinar o restante às instituições assistidas pelo governo. Nesse sentido, a integração de uma política ou programa de agricultura urbana com a política municipal de gestão de resíduos sólidos poderia resultar em uma melhoria da paisagem urbana e a mitigação de problemas graves de saneamento básico e de saúde das cidades, consequência do acúmulo de lixo.

Ademais, convêm ressaltar que estas áreas de produção estão localizadas, em sua maioria, nas áreas periurbanas e os resíduos dos agrotóxicos e adubos sintéticos percolam pelo solo e contaminam o lençol freático que irá abastecer a população, além de prejudicarem o meio ambiente.

Outro resultado a se destacar foi que $79 \%$ dos produtores utilizam alguma técnica de cultivo orgânico, como utilização de adubação verde e orgânica. Assim, pode-se inferir que se houvesse incentivo por parte de políticas públicas para fomentar o uso de técnicas sustentáveis de cultivo, haveria maior produção e fornecimento de alimentos mais saudáveis e ecologicamente corretos. Isto pode ser corroborado pelo fato de que $40 \%$ dos produtores são a favor da produção de alimentos orgânicos e $25 \%$ já os produzem.

\section{CONCLUSÃO}

O fomento ao cultivo de alimentos orgânicos, por meio de políticas públicas, além de ecologicamente correto, seria uma alternativa viável e sustentável para a agregação de valor ao produto. Como consequências diretas, destacam-se o aumento da renda do produtor, a manutenção da sua integridade física e a conservação dos recursos naturais, pelo uso de técnicas agroecológicas, entre elas a não aplicação de agrotóxicos no cultivo.

A agricultura urbana, por meio das práticas agroecológicas e de produção orgânica, constitui importante ação mitigadora de impactos ambientais negativos nas áreas verdes improdutivas e antropizadas, sendo vetor de proteção dos recursos naturais ali existentes, permitindo a coexistência entre os assentamentos humanos e esses recursos naturais.

Observou-se, que a cidade planejada, ou seja, aquele produto de uma ação consciente, o planejamento, considerado por Matus (1996 apud Souza, 2015) [13] como única alternativa de um futuro melhor materializou-se por meio do seu Plano Diretor. Contudo, essa cidade não corresponde à cidade real, aquela que segundo Maricato (1999 in Arantes et al, 2013) [9] existe e sobrevive à margem da legalidade, apresentando-se excluída dos instrumentos de planejamento urbano do Município de São Luís, conforme indicam os resultados da pesquisa de campo. A realidade apreendida na coleta e análise dos dados indica falta de apoio governamental aos produtores, em especial na assistência técnica, na infraestrutura (transportes, estradas), no aporte tecnológico, que deveriam estar contemplados em políticas e programas públicos.

Além disso, evidenciou-se a presença do atravessador que vê oportunidades de incremento de renda nesta atividade. A sua dinâmica consiste em comprar diretamente do Ceasa (que vende produtos importados) e vender nas feiras livres, de acesso mais facilitado em termos burocráticos, 
evitando assim, os custos de produção e de transporte, pois em sua maioria residem em espaços intraurbanos de São Luís.

Como consequência, há um incentivo para a importação de produtos via Ceasa (Cohortifruti) que, além da comercialização direta, tem nos atravessadores um meio de comercialização indireta. A não integração da atividade da agricultura urbana no processo de planejamento de São Luís fomenta o surgimento e manutenção do atravessador como ator social e contribui para o desestímulo do produtor, este o mais prejudicado.

Dessa forma, conclui-se que há grande potencial para o desenvolvimento da horticultura urbana na Ilha de São Luís, porém é evidente a necessidade de discussão e elaboração de políticas públicas nas áreas de infraestrutura urbana (transporte e estradas de boa qualidade), treinamento dos produtores para a sua inserção em programas públicos como o PNAE e PAA, fornecimento de assistência técnica continuada, com foco em agroecossistemas urbanos.

Há uma clara fragmentação espacial entre a produção e a comercialização, que poderia ser minimizada com a cessão de espaços públicos privados, ociosos ou não, para a instalação de hortas comunitárias que permitiria a aproximação entre a produção e comercialização, reduzindo custos.

\section{REFERÊNCIAS BIBLIOGRÁFICAS}

1. Instituto Maranhense de Estudos Socioeconômicos e Cartográficos. 2014. Maranhão em mapas: mapas temáticos do Estado do Maranhão. Disponível em: 〈http://imesc.ma.gov.br/maranhaoemmapas/Home/mapas〉. Acesso em: 18 dez. 2016.

2. Instituto Brasileiro de Geografia e Estatística. Mapa e municípios. 2016. Disponível em: $<$ http://cidades.ibge.gov.br/download/mapa_e_municipios.php?lang=\&uf=ma>. Acesso em: 8 jun. 2016.

3. Altieri M. Agroecologia: a dinâmica produtiva da agricultura sustentável. 4nd ed. Porto Alegre: Editora da UFRGS; 2004.

4. Lepus Gestão e Marketing. Diagnóstico socioeconômico e ambiental do arranjo produtivo local da hortifruticultura na Ilha de São Luís-MA. São Luís: CONSTAT; 2008.

5. Mougeot LJA. Urban agriculture: definition, presence, potentials and risks, and policy challenges. Ottawa: International Development Research Centre; 2000.

6. São Luís (Maranhão). Secretaria Municipal de Agricultura, Pesca e Abastecimento. Superintendência de Comercialização e Abastecimento. Feiras livres mantidas pelo Município de São Luís. 2016. Acesso em: 〈https://www.saoluis.ma.gov.br/subportal_subpagina.asp?site=139>. Acesso em: 16 nov. 2016.

7. Levin J. Estatística aplicada a ciências humanas. 2nd ed. São Paulo: Editora Harbra; 1987.

8. Brasil. Senado Federal. Secretaria Especial de Editoração e Publicações. Subsecretaria de Edições Técnicas. Estatuto da cidade. 3nd ed. Brasília, DF; 2008

9. Arantes O, Vainer C, Maricato E. A cidade do pensamento único: desmanchando consensos. 8nd ed. Petrópolis, RJ: Vozes; 2013.

10. São Luís (Maranhão). Lei $n^{\circ} 4.669$, de 11 de outubro de 2006. Dispõe sobre o Plano Diretor do município de São Luís e dá outras providências. São Luís, 2006. Disponível em: <http://www.gepfs.ufma.br/legurb/LEI\%204669.pdf>. Acesso em: 5 maio 2016.

11. Burnett CFL et al. Planejamento e gestão de cidades no Maranhão: o executivo municipal e o controle do solo urbano. São Luís: EDUEMA; 2016.

12. Cooperativa dos Hortifrutigranjeiros do Maranhão. Sistema de Coleta e Controle de Produtos. Movimentação de produtos por UF. [S.1.], 2016. Movimentação de janeiro a dezembro de 2014 e 2015 e de janeiro a junho de 2016.

13. Souza ML Mudar a cidade: uma introdução crítica ao planejamento e à gestão urbanos. 10. ed. Rio de Janeiro: Bertrand Brasil, 2015. 